\title{
DIÁLOGOS SOBRE A SOCIOEDUCAÇÃO EM TEMPOS DE PANDEMIA
}

\author{
Kátia Aparecida da Silva Nunes Miranda ${ }^{l}$ \\ Universidade Federal de Mato Grosso \\ https://orcid.org/0000-0002-2103-4889 \\ Clóris Violeta Alves Lopes ${ }^{2}$ \\ Universidade Federal do Delta do Parnaíba \\ https://orcid.org/0000-0002-2372-1033
}

\section{RESUMO:}

Nosso objetivo com este texto é convidar a uma reflexão crítica que visa auxiliar no processo de compreensão quanto às práticas socioeducativas, em especial, no atual contexto decorrente da pandemia causada pelo coronavírus (covid-19), momento em que os jovens em regime de privação de liberdade se viram desprovidos de qualquer forma de acesso à educação. Para tanto, os estudos foram realizados sob a ótica dos diálogos estabelecidos pelo Estatuto da Criança e do Adolescente (ECA), do Sistema Nacional de Atendimento Socioeducativo (SINASE) e da discussão sobre as possibilidades metodológicas de manutenção do processo educativo para esses jovens. Com o intuito de garantir sua sustentação, buscou-se aporte teórico em estudiosos como Antônio Costa, para debater sobre as concepções de socioeducação, Paulo Freire e seus ensinamentos sobre dialogicidade, educação cidadã, libertadora e/ ou emancipatória e Elenice Onofre, dentro do viés da educação como inclusão social, utilizando ferramentas da pesquisa bibliográfica, em que se procurou correlacionar as teorias defendidas pelos respectivos autores e as práticas vivenciadas, tomando por base o Centro de Atendimento Socioeducativo de Cuiabá-MT (CASE/MT). A partir das análises reflexivas, os resultados apontam a necessidade premente de aprimorar o entrelaçamento entre as concepções teóricas apresentadas, as normatizações vigentes e as práticas sociopedagógicas, pois só assim será possível garantir um efetivo processo para a reinserção do jovem na sociedade, balizada numa prática que busca evitar reincidências, uma vez que as ferramentas socioeducativas ainda se mostram como o melhor instrumento para auxiliar na emancipação dos jovens em privação de liberdade e, por conseguinte, atuar na transformação social.

Palavras-chave: Jovens em restrição e privação de liberdade. Socioeducação. Diálogos.

\section{ABSTRACT:}

\section{DIALOGUES ABOUT SOCIO-EDUCATION IN PANDEMIC TIMES}

Our objective with this text is to invite a critical reflection that aims to assist in the process of understanding socio-educational practices, especially in the current context resulting from the pandemic caused by the coronavirus (COVID-19), at which time young people in deprivation of liberty regime were devoid of any form of access to education. For this purpose, the studies were conducted from the perspective of the dialogues established by the Statute of the Child and Adolescent - ECA, the National System of Socioeducational Care - SINASE, and the discussion about the methodological possibilities of maintaining the educational process for these young people. In order to guarantee its support, we sought theoretical

\footnotetext{
1 Universidade Federal de Mato Grosso (UFMT). Doutorado em Educação (UFSCar). Núcleo de Estudos e Pesquisa Emancipatória em Linguagem (Nepel/UFMT) e integrante do Núcleo de Investigação e Práticas em educação nos espaços de restrição e privação de liberdade (EduCárceres/UFSCar). E-mail: katia-nmiranda@hotmail.com

2 Universidade Federal do Delta do Parnaíba (UFDPar). Doutorado em Educação (UFSCar); Núcleo de Investigação e Práticas em educação nos espaços de restrição e privação de liberdade (EduCárceres/UFSCar). E-mail: cloris-carlos@uol.com.br
} 
contribution to scholars such as Antônio Costa, to discuss the conceptions of socio-education, Paulo Freire and his teachings on dialogicity, citizen education, liberating and/or emancipatory and Elenice Onofre, within the bias of education as social inclusion, using tools of bibliographic research, in which we sought to correlate the theories defended by the respective authors and the practices experienced, based on the Socio-educational Care Center of Cuiabá-MT (CASE/MT). Based on reflective analyzes, the results point to the urgent need to improve the intertwining between the theoretical concepts presented, the current norms and socio-educational practices, because only then will it be possible to guarantee an effective process for the reintegration of young people into society, based on a practice which seeks to avoid recidivism, since socio-educational tools are still the best instrument to assist in the emancipation of young people in deprivation of liberty and, therefore, to act in social transformation.

Keywords: Young people in restriction and deprivation of liberty. Socio-education. Dialogues.

\section{RESUMEN:}

\section{DIÁLOGOS SOBRE SOCIO EDUCACIÓN EN TIEMPOS DE PANDEMIA}

Nuestro objetivo con este texto es invitar a una reflexión crítica que tiene como objetivo ayudar en el proceso de comprensión de las prácticas socioeducativas, especialmente en el contexto actual derivado de la pandemia provocada por el coronavirus (covid-19), época en la que los jóvenes en situación de privación de libertad se encontraron sin ninguna forma de acceso a la educación. Para ello, los estudios se realizaron desde la perspectiva de los diálogos establecidos por el Estatuto de la Niñez y la Adolescencia (ECA), el Sistema Nacional de Asistencia Social y Educativa (SINASE) y la discusión sobre las posibilidades metodológicas de mantener el proceso educativo de estos jóvenes. Para garantizar su apoyo, se buscó un aporte teórico de académicos como Antonio Costa, para debatir los conceptos de socio educación, Paulo Freire y sus enseñanzas sobre dialogicidad, educación ciudadana, liberadora y/o emancipadora y Elenice Onofre, dentro del sesgo de la educación como inclusión social, utilizando herramientas de investigación bibliográfica, en las que se intentó correlacionar las teorías defendidas por los respectivos autores y las prácticas vividas, con base en el Centro de Servicio Socioeducativo Cuiabá - MT (CASE / MT). A partir de análisis reflexivos, los resultados apuntan a la urgente necesidad de mejorar el entrelazamiento entre los conceptos teóricos presentados, la normativa vigente y las prácticas socio pedagógicas, pues solo así será posible garantizar un proceso efectivo de reinserción de los jóvenes en la sociedad, a partir de una práctica. que busca evitar la reincidencia, ya que las herramientas socio educativas siguen siendo el mejor instrumento para ayudar en la emancipación de los jóvenes en privación de libertad y, por tanto, actuar en la transformación social.

Palabras clave: Juventud en restricción y privación de libertad. Socio educación. Diálogos

\section{Introduzindo o assunto}

Para compreender as questões que envolvem a socioeducação, vale destacar que, qualquer que seja o tipo de educação, ela é, por natureza, proeminentemente social (COSTA, 2004).

Portanto, o conceito de socioeducação privilegia o aprendizado para o convívio social e para o exercício da cidadania. Assim, empreendem-se ações para a materialidade de propostas que implicam uma nova forma de o indivíduo relacionar-se consigo e com o mundo.

Com a Lei n. ${ }^{\circ}$ 8.069/1990 (Estatuto da Criança e do Adolescente - ECA) e a ratificação do Brasil como signatário da Convenção sobre os Direitos da Criança no mesmo ano, emergem dispositivos legais que garantem ao público infanto-juvenil, enquanto sujeitos de direito, a proteção integral, de forma que os seus interesses passam a ter prevalência sobre qualquer outro. 
Destaca-se a sua premissa em promover mudanças conceituais e trazer inovações para a construção de políticas públicas e sociais voltadas para a criança e o jovem, com reflexos, inclusive, para a questão infracional, responsabilizando o jovem que cometeu algum tipo de infração, o qual passará a responder sob a forma de medidas socioeducativas.

Tal prática ganhou reforço com a Lei n ${ }^{\circ}$ 12.594/2012 (Sistema Nacional de Atendimento Socioeducativo - SINASE), que dispôs sobre a advertência, obrigação de reparar danos, prestação de serviços, liberdade assistida, inserção em regime de semiliberdade ou a internação em estabelecimento educacional a serem aplicadas ao jovem infrator.

No entanto, tais medidas, para além da sanção, devem contar com práticas de natureza sociopedagógica (social, pedagógica, educativa) que possibilitem ao jovem a oportunidade de construir novos valores e perspectivas de vida.

Com o ECA, além de ser apresentada uma nova concepção da infância e da adolescência, resgatando-se direitos e garantias constitucionais, estabelecem-se medidas socioeducativas a serem aplicadas, o que permite uma reorientação na atenção aos jovens. Assim, quando um jovem passa a ser atendido, ao mesmo tempo em que se aplica algum tipo de sanção, ofertase, mediante a socioeducação, a garantia de suas necessidades e direitos.

Portanto, abordar acerca das fragilidades enfrentadas nas políticas públicas destinadas à socioeducação, questionar a eficácia de seu cumprimento, problematizar a obrigação de estarem orientadas pelos princípios educacionais, pedagógicos, sociais e humanos são meios de não naturalizar a cultura de encarceramento juvenil que pode estar se tornando uma auspiciosa máquina para o aprofundamento das violências na vida dos jovens.

No entanto, no contexto atual, com a pandemia causada pelo coronavírus (covid-19) que afeta o mundo todo, as instituições e a sociedade, de modo geral, têm se confrontado com uma nova conjuntura, merecendo um destaque especial o campo socioeducativo.

Verifica-se, pois, uma grande dificuldade em trabalhar pedagogicamente com os jovens inseridos nesse meio, fazendo-se necessário remodelar urgentemente a forma de convivência social e institucional para que ocorra uma adequação das práticas a serem desenvolvidas nos espaços de socioeducação, pautadas no repensar e ressignificar o direito à vida aos casos concretos que o plano fático nos traz.

Nesse contexto, propomos refletir criticamente, com este artigo, acerca do ECA e SINASE, a partir das políticas públicas destinadas à socioeducação nesse período pandêmico, mostrando, ainda, quais são as medidas que estão sendo tomadas pelos governos federal e estadual para mitigar o problema no sistema socioeducativo. 
Para tanto, utilizamos o aporte teórico de Costa $(2001,2004)$, Freire $(2005,2007)$ e Onofre $(2013,2015)$, por meio da ferramenta metodológica da pesquisa bibliográfica, e procuramos correlacionar teoria e prática tomando por base o Centro de Atendimento Socioeducativo de Cuiabá-MT, visando aprofundar a investigação sobre o tema, que possibilita a estruturação do embasamento teórico utilizado.

O trabalho está dividido em três partes. Na primeira, discutimos sobre a socioeducação, diálogos e educação nos espaços de privação de liberdade, privilegiando as concepções de Antônio Costa, Paulo Freire e Elenice Onofre; na sequência, apresenta-se uma reflexão sobre a socioeducação existente no Brasil e em Mato Grosso; em seguida, discorremos sobre a opção metodológica, amparados na pesquisa bibliográfica, e arrematamos com os possíveis caminhos em tempos de pandemia, a fim de delinearmos uma reflexão crítica em relação às políticas públicas inerentes à socioeducação.

\section{Diálogos e socioeducação: pressupostos teóricos}

Os pressupostos teóricos que sustentaram este estudo estão ancorados na concepção da educação que pretende ser formadora de um sujeito autônomo. Nessa perspectiva, as contribuições dos autores como Costa $(2001,2004)$, Freire $(2005,2007)$ e Onofre $(2013,2015)$ possibilitam análises que se entrelaçam na inter-relação dialética entre mundo, ser humano, educação cidadã e socioeducação.

De acordo com Costa (2004), qualquer que seja o tipo de educação, ela é, por natureza, proeminentemente social. O conceito de socioeducação privilegia, por assim dizer, o aprendizado para o convívio social e exercício da cidadania, fazendo-se necessário, pois, que as políticas públicas sociais estejam constantemente voltadas para a prática e desenvolvimento de ações que visem materializar propostas que impliquem em uma nova forma de o indivíduo relacionar-se consigo e com o mundo.

Concebe-se a socioeducação como o educar para o coletivo, no coletivo e com o coletivo (COSTA, 2004), o que reforça a natureza sociopedagógica existente nos preceitos do ECA, quando da adoção de um projeto social compartilhado, voltado ao desenvolvimento e fortalecimento da identidade pessoal, cultural e social do jovem.

Para Costa (2004), a socioeducação divide-se em duas grandes modalidades: uma, de caráter protetivo, voltada para as crianças, jovens e adultos em circunstâncias especialmente difíceis, em razão da ameaça ou violação de seus direitos, por ação ou omissão da família, da sociedade, do Estado ou, até mesmo, da sua própria conduta, que os leva a se envolverem em situações que 
implicam em risco pessoal e social; e outra, especificamente voltada para o trabalho social e educativo, destinada aos jovens em cumprimento de medida socioeducativa.

A socioeducação está alicerçada no pressuposto da formação integral do ser humano, contemplando todas as dimensões do ser. Essa educação, para além da formação escolar e profissional, está profundamente ligada a uma nova forma de pensar e dialogar com o jovem.

Trata-se de um movimento emancipador do sujeito que, para Costa (2004), está articulado com um projeto de socioeducação que deve ser aliado à educação geral e profissional. No entanto, para que isso ocorra, as ações educativas devem exercer uma influência edificante sobre a vida do jovem, criando condições para que ele cumpra tarefas bem peculiares dessa fase da vida.

A partir de Freire (2007), entende-se a socioeducação pelo diálogo estabelecido entre educador e educando, fundamental para a problematização das situações reais vividas pelo jovem, que o leva a perceber o problema originário e a buscar por mudanças. Para tanto, essa relação dialógica deve oportunizar a educação como prática de humanização, independentemente do espaço no qual o jovem se encontre.

Freire (2005) refere-se à importância da dialogicidade, posto que, de acordo com o autor, o diálogo entre educador e educando deve ser considerado como elemento fundamental para a problematização de situações reais vividas pelo aluno.

No entendimento de Freire (2005), problematizar consiste em abordar questões que emergem de situações que fazem parte da vivência dos educandos; é desencadear uma análise crítica sobre a 'realidade problema' para que o educando perceba a questão e reconheça a necessidade de mudanças.

Conforme Freire (2005), o diálogo é a forma mais segura para a educação e libertação de todos os homens e mulheres — opressores e oprimidos —, apontando que, a partir da arte do diálogo e da contraposição de opiniões, é possível alcançar novas ideias. Em sua teoria, fica claro que o diálogo consiste em uma relação horizontal entre as pessoas envolvidas em uma relação.

Assim, com o propósito de vencer a situação de desumanização dos indivíduos, torna-se fundamental o processo de educação de tal maneira que possam tomar consciência de sua condição de seres desumanizados e buscar alcançar sua humanização. Sob esse viés, apresenta-se o processo de conscientização e diálogo por meio do qual os seres humanos poderão tornar-se sujeitos no processo educativo, tal como na construção de sua humanidade.

Onofre (2015) também aponta para a necessidade de encontrar meios que auxiliem a desenvolver atividades para os jovens em restrição e privação de liberdade, observando que, enquanto se trabalha o princípio fundamental da educação por essência transformadora e libertadora, estabelece-se a cultura de privação de liberdade, levando à adaptação e à privação de liberdade. 
Para Onofre (2013), as políticas de inclusão em espaços de privação de liberdade provocam algumas inquietações. Uma delas é a de promover a problematização das questões dos invisíveis no paradigma da segurança, característico desse espaço.

Nesse sentido, o que se propõe é ver a educação no espaço de privação de liberdade pela perspectiva dos direitos humanos, porque ela constitui um valor em si mesma, sendo um conjunto de ferramentas e de capacidades que ampliam as possibilidades de implementação de projetos que contribuam para a inclusão social, cultural e econômica das pessoas aprisionadas (ONOFRE, 2013, p. 52)

Segundo Onofre (2013), o Estado tem a competência e responsabilidade de promover práticas de fortalecimento e controle de políticas públicas no sentido de que os direitos humanos básicos sejam garantidos, com igualdade para todos os indivíduos, incluindo-se aqueles que se encontram em privação de liberdade (ONOFRE, 2013, p. 52).

Nesse sentido, Onofre (2015) aponta que tais políticas devem estar evidenciadas no cotidiano dos espaços de privação de liberdade, fazendo dessas instituições espaços educativos e tendo a educação como alicerce desse processo. Para tanto, pensar o universo da educação significa ir além da educação escolar, somando-se a ela as experiências educativas que ocorrem no cotidiano das pessoas, por meio do relacionamento com outros indivíduos e com o seu ambiente (ONOFRE, 2013).

Nessa perspectiva, alinhando-se com a concepção de Costa, Freire e Onofre, os autores sugerem o engajamento em ações práticas para que, de fato, haja transformação social, indicando possibilidades de aplicação dessa mudança na socioeducação, edificadas com base no desvelamento dos problemas sociais e originadas das práticas sociais com o objetivo de buscar solução e superação.

\section{Reflexões acerca da socieducação em tempos de pandemia: con- texto brasileiro e mato-grossense}

Com a pandemia mundial causada pelo coronavírus (covid-19), as instituições e a sociedade, de modo geral, têm se deparado com um novo cenário educacional. Na socioeducação, verifica-se uma grande dificuldade em trabalhar pedagogicamente com os jovens inseridos nesse meio, buscando novas abordagens para a convivência social e institucional, adequando as metodologias e práticas a serem adotadas nos locais que contam com jovens em situação de privação de liberdade. Tais premissas devem buscar sustentação no ato de repensar os direitos inerentes aos jovens em face da atual situação pandêmica. 
Conforme levantamento do Conselho Nacional do Ministério Público (CNMP), em 2019, o Brasil contava com 18.086 jovens em situação de privação de liberdade, distribuídos em 330 unidades de socioeducação.

Referido estudo destacou que essas unidades totalizavam 16.161 vagas, mostrando a distorção entre o número de jovens e de vagas, que evidencia o principal impacto da pandemia no sistema socioeducativo - a superlotação.

Consequentemente, essa distorção dificulta o atendimento às recomendações da Organização Mundial da Saúde (OMS) e do Ministério da Saúde (MS) para prevenção da covid-19, que compreende, basicamente, o distanciamento físico, a não aglomeração de pessoas e rotinas constantes de higienização. Registra-se, ainda, que o não cumprimento de tais medidas pode levar mais pessoas a óbito em decorrência da doença.

A Constituição Federal de 1988, no seu artigo 227, garante ao jovem a proteção integral, que deve ocorrer com a adoção de providências no âmbito dos três poderes (Executivo, Legislativo e Judiciário) e com prioridade absoluta, com vistas à importância do pleno desenvolvimento dos indivíduos, motivo pelo qual os ditames constitucionais servem de amparo e dão especial relevância à temática, complementada pelo ECA e SINASE.

A hipótese fática atual deve servir como fundamento para fortalecer a proteção ao jovem em situação e privação de liberdade, e não como reforço para o caráter punitivo e segregação do jovem. A privação de liberdade com a aplicação de medida não pode se traduzir em mero punitivismo estatal e deve sempre visar à reinserção social.

O Conselho Nacional de Justiça, diante disso, editou a Recomendação n. ${ }^{\circ}$ 62/2020, cuja normativa tenta dar um novo prisma de aplicação, com um (re)pensar crítico que se afasta do mero punitivismo e privação de liberdade em sede infracional.

Destarte, a Resolução n. ${ }^{\circ}$ 75/2020, da Secretaria da Justiça, Família e Trabalho, que disciplina as disposições do Decreto Estadual n. ${ }^{\circ}$ 4.230/2020, com a finalidade de instituir e adotar medidas e providências como Plano de Contingência de Prevenção ao contágio pelo vírus da covid-19, em seu artigo 17, inciso VI, determina que os adolescentes que se encontram em cumprimento de medida socioeducativa de semiliberdade podem, durante o período de contingenciamento, permanecer em suas casas diante da grave situação que se alastra pelo país com a disseminação do vírus, como medida de prevenção e segurança.

Já o Conselho Nacional dos Direitos da Criança e do Adolescente (CONANDA), em consonância com a Resolução n. ${ }^{\circ} 313$ do Conselho Nacional de Justiça (CNJ), de 19 de março de 2020, que estabeleceu critérios para uniformizar o funcionamento dos serviços judiciários, com o objetivo de prevenir o contágio pela covid-19 e garantir o acesso à justiça durante o perí- 
odo emergencial, recomendou a observação da resolução em comento, destacando em seu item 13 a possibilidade de revisão das medidas socioeducativas imputadas e sua progressão para o meio aberto, a suspensão das medidas junto aos grupos de riscos, dentre outros aspectos, como garantir a comunicabilidade dos adolescentes com suas famílias por meio remoto; a prática de medidas socioeducativas por meios digitais; a higienização do ambiente, bem como o controle e informação ao Estado sobre o cumprimento das medidas apontadas pela Resolução n. ${ }^{\circ}$ 62/2020 do CNJ (BRASIL, 2020b).

Asseveramos que a posição do CNJ e do CONANDA é efetivamente uma predileção por medidas restritivas (meio aberto) ou por cumprimento de medida domiciliar, isso porque é reconhecido que o sistema socioeducativo no Brasil sofre com superlotação e estruturas precárias.

Mesmo que em alguns estados brasileiros não haja superlotação, é importante destacar que o sistema socioeducativo não tem condições de evitar a propagação do coronavírus, dada a arquitetura das unidades socioeducativas que conta com alojamentos próximos uns dos outros, quase sempre sem ventilação e iluminação.

Nessa mesma direção, em âmbito estadual, no que tange ao sistema educacional de Mato Grosso, medidas sobre reorganização dos calendários escolares e realização de atividades pedagógicas não presenciais durante o período de pandemia da covid-19 foram tomadas, afetando todas as modalidades, desde as de ensino: ensino médio, Educação de Jovens e Adultos (EJA), educação especial, educação do campo, quilombola e indígena, de povos tradicionais, até as especializadas, como o sistema socioeducativo, sistema penitenciário, classes e ambientes hospitalares, educação integral e atendimento aos imigrantes.

Por meio da proposta no Parecer n. ${ }^{\circ}$ 5/2020-CNE/CP, de 28 de abril de 2020, pelo Conselho Nacional de Educação, tanto o Conselho Estadual de Educação de Mato Grosso (CEE-MT) quanto a Secretaria de Estado de Educação do estado (SEDUC/MT), resguardadas as especificidades locais, tomaram medidas no sentido de mitigar localmente a proposta de parecer emitida pelo Conselho Nacional de Educação.

Assim, o sistema socioeducativo permanece sem aulas on-line e com material impresso, semanalmente, para todos os jovens. Essa medida tem o objetivo de regulamentar normas a serem adotadas pelas instituições pertencentes ao Sistema Estadual de Ensino, enquanto perdurar a situação de pandemia pelo novo coronavírus (covid-19).

Nesse sentido, a Secretaria de Estado de Segurança Pública (SESP-MT), instituição responsável pela execução da medida socioeducativa em meio fechado no estado de Mato Grosso, mantém restringido o acesso de pessoas com sintomas de gripe e daquelas consideradas do grupo de risco. 
Também estão mantidas as suspensões de: transferências de jovens entre Centros de Atendimento Socioeducativo e interestaduais, salvo casos excepcionais, devidamente autorizados pelo superintendente de Administração Socioeducativa; atividades religiosas, assim como aquelas que necessitam do acesso de pessoas externas para a promoção de projetos sociais; assistência cultural, realização de cursos e outras atividades coletivas que possam provocar a aglomeração de pessoas, resguardando, assim, tanto os adolescentes quanto os servidores.

Está proibido o recebimento de jovens oriundos de outros estados e países, assim como não é possível, no momento, o recebimento de alimentos e posterior entrega aos jovens. Outra limitação imposta refere-se à deliberação de que as unidades devem seguir a determinação de suspender as atividades presenciais escolares.

Além disso, foi mantido o atendimento psicossocial individualizado aos adolescentes privados de liberdade apenas em casos emergenciais ou urgentes, respeitando as recomendações do Ministério da Saúde quanto à prevenção do contágio pelo coronavírus, especialmente, a distância mínima e o ambiente ventilado.

Retomando as normativas do CNJ, verifica-se que elas recomendam aos CASEs que mantenham as atividades educacionais, físicas, lúdicas, de lazer, recreativas, bem como incentivem a leitura, os trabalhos manuais, os filmes, os jogos, entre outros, em menor número de adolescentes, obedecendo às recomendações do Ministério da Saúde quanto ao combate da covid-19.

Assim, necessário se faz encontrar soluções que garantam a continuidade e inclusão de novas práticas para atender ao processo socioeducacional desses jovens em situação de privação de liberdade.

\section{Opções metodológicas}

Optou-se pela abordagem qualitativa, por meio de uma pesquisa bibliográfica, que tem o documento como objeto de investigação. Assim, a pesquisa foi desenvolvida com base em material já elaborado, constituído principalmente de livros, artigos científicos, normativas, decretos e recomendações (GIL, 2008).

Nesse sentido, a pesquisa bibliográfica é realizada buscando efetuar o levantamento de um saber disponível sobre teorias e concepções, com o intuito de analisar, produzir ou explicar um objeto que está sendo investigado. Assim sendo, esse estudo, por meio da pesquisa bibliográfica, analisou as principais teorias e autores da temática abordada com diferentes finalidades (CHIARA et al., 2008), entre elas, ações sociopedagógicas e o compromisso ético-político com a sociedade em prol da construção de outro mundo possível. 


\section{Possíveis caminhos}

Seguindo as diretrizes instituídas pelo Conselho Nacional de Justiça (CNJ), levando em consideração as recomendações expedidas pelos órgãos públicos e pela Organização Mundial da Saúde (OMS), de caráter preventivo, assegurando a saúde dos jovens e de seus familiares, preconizadas no artigo 227 da Constituição Federal de 1988 (CF/88), em observância à proteção integral do jovem, seja por questão humanitária ou em decorrência do princípio da homogeneidade, tem-se um novo olhar sob a aplicação e execução das medidas socioeducativas em tempos de pandemia.

Segundo a Recomendação n. ${ }^{\circ}$ 62/2020 do CNJ, as instituições devem elaborar planos de contingência explicitando as rotinas e os protocolos que devem ser adotados. Tal plano limita-se basicamente a descrever os aspectos da pandemia, as características da covid-19 e elencar quais equipamentos de proteção devem ser utilizados.

Logo, visualiza-se um novo aspecto na aplicabilidade da medida socioeducativa de privação de liberdade, uma vez que a situação trazida pelo cenário atual pandêmico conduz a uma nova percepção das instituições e de suas ações sociais, bem como obriga os profissionais envolvidos com a educação a achar mecanismos que possam ser adequados à nova realidade vivenciada, por meio da introdução de disposições normativas que possibilitem e ampliem os recursos metodológicos utilizados para lidar com as adversidades e superar os tensionamentos decorrentes da situação atual.

Para tanto, é preciso ofertar atividades culturais e educacionais aos jovens em situação de privação de liberdade, por meio de recursos, ainda que on-line, garantindo a continuidade das ações socioeducativas a esses jovens, despertando neles a reflexão de quais são os papéis disponíveis a eles neste conturbado período, quais papéis estão efetivamente experimentando e o que querem assumir como compromisso para suas vidas no futuro, com a finalidade de que façam escolhas de forma consciente e atuante, sem se sentirem excluídos mesmo em tempos tão difíceis.

O direito à educação, saúde e convivência familiar no sistema socioeducativo durante a pandemia deve ser respeitado e garantido, para além dos principais desafios já enfrentados em relação à articulação em rede para o fortalecimento das medidas em meio aberto e quanto ao uso de equipamentos de proteção individual pelos funcionários e jovens.

A partir dessa compreensão, verifica-se que é papel do Estado atuar para o resgate da cidadania do jovem em situação de privação de liberdade. 


\section{Considerações}

Vivemos um momento em que se faz imprescindível a desconstrução das experiências danosas, reinventando-as. Repensar o sistema socioeducativo é preciso e necessário, entretanto, isso não significa a sua extinção ou agravamento.

Não se pode pensar em uma sanção severa, por meio da privação de liberdade, para resolver o problema da criminalidade e violência em nosso país. A proposta não é incentivar a defesa do endurecimento do ECA, por exemplo, mas, sim, manter viva uma reflexão constante acerca da capacidade sociopedagógica que possui esse sistema.

Esse dever de desconstrução da punição e não aceitação é um ato de resistência e luta pela garantia dos direitos desses jovens. É crucial, porém, para a construção de políticas públicas sólidas e eficazes ao atendimento socioeducativo, que se efetivem ações conjuntas envolvendo diversos atores como: Poder Executivo (federal, estadual e municipal), Poder Judiciário, Ministério Público e a sociedade civil, dando abertura ao princípio da incompletude institucional.

Dessa forma, em tempos de pandemia, tão importante quanto a responsabilização do jovem transgressor, é assegurar-lhe os direitos e garantias fundamentais, desde a fase de investigação/apuração dos fatos, com o devido respeito ao processo legal e condições especiais da área infanto-juvenil, até o final da execução da medida. Para tanto, é essencial garantir a eficácia dos direitos do jovem que permaneceu em privação de liberdade durante todo o período da pandemia.

A socioeducação decorre da perspectiva de que o desenvolvimento humano deve se dar de forma integral, contemplando todas as dimensões do ser. É a opção por uma educação que vai além do processo escolar e profissional, trata-se de uma educação humanizadora, libertadora e emancipadora, que valoriza os sujeitos como construtores de seus conhecimentos, prevalecendo entre os pares uma relação dialógica. Essa ideia está intimamente associada a uma nova forma de pensar e abordar o trabalho com os jovens.

\section{Referências}

BRASIL. Lei no 8.069/1990. Estatuto da Criança e do Adolescente (ECA). Brasília/DF, 1990.

BRASIL. Lei 12.594/2012. Sistema Nacional de Atendimento Socioeducativo (SINASE).

Brasília/DF: Casa Civil, 2012. Disponível em: http:/www.planalto.gov.br/ccivil_03/_ato20112014/2012/lei/112594.htm. Acesso em: 30 dez. 2020.

BRASIL. CNJ. Conselho Nacional de Justiça. Orientação técnica para inspeção pelo Poder Judiciário dos espaços de privação de liberdade no contexto da pandemia. 2020. Disponível em: https://www.cnj.jus.br/wp-content/uploads/2020/05/Orienta\%C3\%A7\%C3\%A3o-CNJ-Final.pdf. Acesso em: 30 dez. 2020. 
BRASIL. CONANDA. Conselho Nacional dos Direitos da Criança e do Adolescente. Recomendações do CONANDA para a proteção integral a crianças e adolescentes durante a pandemia do covid-19. 2020b. Disponível em: https://crianca.mppr.mp.br/arquivos/File/ legis/covid19/recomendacoes_conanda_covid19_25032020.pdf. Acesso em: 30 dez. 2020.

BRASIL. CNE/CP. PARECER N ${ }^{0}$ 5/2020, de 28 de abril de 2020 sobre reorganização dos calendários escolares e realização de atividades pedagógicas não presenciais durante o período de pandemia da COVID-19. Disponível em: https://undime.org.br/noticia/30-04-2020-19-39-cne-divulga-parecer-comorientacoes-sobre-a-reorganizacao-do-calendario escola atividades pedagogicas-nao-presenciais-em-razao-da-pandemia-da-covid-19. Acesso em: 6 nov. 2020.

COSTA, A. C. G. da. Pedagogia da Presença: da Solidão ao Encontro. Belo Horizonte, MG: Modus Faciendi, 2001.

COSTA, A. C. G. Os regimes de atendimento no estatuto da criança e do adolescente: perspectivas e desafios. Secretaria Especial de Direitos Humanos. 2004.

CHIARA, I. D. et al. Normas de documentação aplicadas à área de Saúde. Rio de Janeiro: Editora E-papers, 2008.

DICK, Bob. Como conduzir e relatar a pesquisa-ação. In: Richardson, R. J. Pesquisa-ação Princípios e Métodos, João Pessoa: Editora Universitária/UFPB, 2003.

FREIRE, Paulo. Pedagogia da Esperança. Rio de Janeiro: Paz e Terra, 1992.

FREIRE, P. Pedagogia do Oprimido. Rio de Janeiro: Paz e Terra, 2005.

GIL, A. C. Como elaborar projetos de pesquisa. 4. ed. São Paulo: Atlas, 2008.

ONOFRE, Elenice Maria Cammarosano; JULIAO, Elionaldo Fernandes. A educação na prisão como política pública: entre desafios e tarefas. Educ. Real. [online]. vol.38, n.1, p. 51- 69, 2013.

ONOFRE, E. M. C. Educação Escolar para Jovens e Adultos em Situação de Privação de Liberdade. Cad. Cedes, Campinas, v. 35, n. 96, p. 239-255, maio-ago, 2015.

MATO GROSSO. Secretaria de Estado de Educação (SEDUC). Aprendizagem Conectada. Disponível em: http://www.aprendizagemconectada.mt.gov.br/ensino-fundamental. Acesso em: 06 nov. 2020.

THIOLLENT, M. Metodologia da pesquisa-ação. São Paulo: Cortez, 2011.

Recebido em: 16 de janeiro de 2021.

Publicado em: 20 de abril de 2021.

Este é um artigo publicado em acesso aberto sob uma licença Creative Commons. 